\title{
Subcellular Fractionation of the Colourless Alga Polytomella caeca by Differential and Zonal Centrifugation
}

\author{
By ROSEMARY A. COOPER* AND D. LLOYD \\ Department of Microbiology, University College, \\ Newport Road, Cardiff, CF I $3 N R$
}

(Accepted for publication I5 March 1972)

\begin{abstract}
SUMMARY
Homogenates from Polytomella caeca were fractionated by differential centrifugation. All the mitochondria (located by measurement of cytochrome $c$ oxidase) and most of the peroxisomes (located by measurement of catalase) sedimented at $10^{5} \mathrm{~g} \mathrm{~min}$. Most of the NADPH-cytochrome $c$ oxidoreductase, IDPase and acid $p$-nitrophenyl phosphatase were still present in the supernatant. This supernatant also contained a cytochrome $b$, cytochromes $P$-450 and $P$-416. Zonal centrifugation indicated that catalase and cytochrome oxidase were entirely sedimentable at $6 \times 10^{6} \mathrm{~g}$ min and that NADPH- and antimycin A-insensitive NADH-cytochrome $c$ oxidoreductases were not mitochondrial. Peroxisomes $(\rho=\mathrm{I} \cdot 25)$ were separated from mitochondria $(\rho=\mathrm{I} \cdot 20)$ by both rate and isopycnic-zonal centrifugation. Two zones of acid $p$-nitrophenyl phosphatase activity were detected, one at $\rho=$ $\mathrm{I} \cdot \mathrm{I} 5$ and the other at $\rho=\mathrm{I} \cdot 2 \mathrm{I}$, but no other acid hydrolases were found. Separation, of polysomes and various microsomal enzymes (IDPase, acid p-nitrophenyl phosphatase, NADH- and NADPH-cytochrome $c$ oxidoreductases) was also achieved.
\end{abstract}

\section{INTRODUCTION}

The flagellate Polytomella caeca may be regarded either as a protozoan or as a colourless alga of the Order Volvocales (Pringsheim, 1955). Grown aerobically on a mineral saltsthiamine medium with acetate as sole carbon source, this organism has highly developed mitochondria which, after gentle mechanical disruption of the fragile pellicle, may be isolated in a reasonably intact state (Lloyd \& Chance, r968; Lloyd, Evans \& Venables, 1968). The ease of breakage of this organism makes it convenient for the study of isolated organelles. In the present investigation, we separate and characterize some of the membrane systems other than mitochondria preserved in cell-free homogenates. Preliminary accounts of some of this work have previously been published (Cooper, Jones, Venables \& Lloyd, I969; Cartledge, Cooper \& Lloyd, I97I).

\section{METHODS}

Maintenance and harvesting of the organism. Polytomella caeca Pringsheim was obtained in axenic culture from the Culture Collection of Algae, Department of Botany, Indiana University, Bloomington, Indiana, U.S.A. (catalogue no. LB 192). The organism was grown with gentle forced aeration as previously described (Lloyd \& Chance, I968) in volumes up to 30 1. The alga was harvested in the late exponential phase of growth by continuous flow centrifugation (Lloyd, Evans \& Venables, 1968).

* Present address: Department of Biology and Chemistry, Llandaff College of Technology, Western Avenue, Cardiff, $\mathrm{CF}_{5} 2$ YB. 
Preparation of homogenates. Except where otherwise stated, the homogenization buffer contained $0.32 \mathrm{M}$-sucrose-10 mM-tris- $\mathrm{HCl}-0.5 \mathrm{mM}^{-} \mathrm{MgCl}_{2}(\mathrm{pH} 7.4)$; all procedures were carried out at $4{ }^{\circ} \mathrm{C}$. The organisms were suspended in 5 vol. of this buffer, and subjected to 8 to 12 gentle complete strokes in a hand operated homogenizer (Kontes Glass Co., Vineland, New Jersey, U.S.A.) fitted with a type B plunger (0.01 cm clearance). This treatment broke about $70 \%$ of the organisms. The crude extract thus obtained was centrifuged for Io min at $800 \mathrm{~g}\left(r_{\mathrm{av}}=7.6 \mathrm{~cm}\right)$ in an $8 \times 50 \mathrm{ml}$ rotor of an M.S.E. ' 17 ' centrifuge to remove unbroken organisms, nuclei, starch granules and pellicles. The supernatant was termed 'whole homogenate' (WH).

Fractionation of whole homogenates by differential centrifugation. The whole homogenate was centrifuged for $10 \mathrm{~min}$ at $10000 \mathrm{~g}\left(r_{\mathrm{av}}=7.6 \mathrm{~cm}\right)$ in the $8 \times 50 \mathrm{ml}$ rotor of the M.S.E. ' 17 ' centrifuge. The supernatant $\left(S_{1}\right)$ was carefully decanted, leaving the first pellet $\left(P_{1}\right)$, and centrifuged for $20 \mathrm{~min}$ at $20000 \mathrm{~g}$ in the same centrifuge. This supernatant $\left(\mathrm{S}_{2}\right)$ was decanted from the first 'microsomal' pellet $\left(\mathrm{P}_{2}\right)$ and centrifuged for $60 \mathrm{~min}$ at $106000 \mathrm{~g}\left(r_{\mathrm{ap}}=6 \mathrm{~cm}\right)$ in the $8 \times 10 \mathrm{ml}$ rotor of an M.S.E. ' 40 ' centrifuge, giving a pellet $\left(\mathrm{P}_{3}\right)$ and a final supernatant $\left(\mathrm{S}_{3}\right)$. Pellets were uniformly resuspended in known volumes of the homogenization buffer immediately on collection.

Fractionation by zonal centrifugation. Zonal centrifugations were performed in a B XIV rotor (Anderson et al. 1967) in an M.S.E. '40' centrifuge as described by Lloyd et al. (197I). The only modification of this procedure was that, except where otherwise stated, all sucrose solutions contained $0.5 \mathrm{mM}-\mathrm{MgCl}_{2}$ and were buffered to $\mathrm{pH} 7.4$ with $10 \mathrm{mM}$-tris- $\mathrm{HCl}$. Centrifugation conditions are detailed in the results section. Absorbance of the effluent, obtained on unloading, was monitored continuously at $520 \mathrm{~nm}$ or at $260 \mathrm{~nm}$. Fractions $\left(\mathrm{I} 0 \mathrm{ml}\right.$ ) were collected at $4{ }^{\circ} \mathrm{C}$. Sucrose concentrations were measured using a refractometer; density and viscosity values were calculated from the data of de Duve, Berthet \& Beaufay (1959).

Enzyme assays. Assay conditions for acid p-nitrophenyl phosphatase (EC. 3.1.3.2), catalase (EC. I . I I I .6), NADH- (EC. I·6·2·2) and NADPH- (EC. I .6.2.3) cytochrome $c$ oxidoreductases have been previously described (Lloyd et al. 197I). The following methods were employed for malate dehydrogenase (EC. I.I.I.37), Ochoa (I955); cytochrome $c$ oxidase (EC. 1.9.3.I), Smith (1955); succinate-cytochrome $c$ oxidoreductase, Mahler (I955) and IDPase* (EC. 3.6.1.6), Novikoff \& Heus (I963). Assays for acid p-nitrophenyl phosphatase and IDPase were carried out at $25^{\circ} \mathrm{C}$, while all spectrophotometric assays were performed at room temperature $\left(18^{\circ} \mathrm{C} \pm 2{ }^{\circ} \mathrm{C}\right)$ using a Cary model 14 recording spectrophotometer fitted with a fine slide wire with a full scale deflection corresponding to an extinction of 0.1 . Antimycin A was used as a methanolic solution ( $\mathrm{Img} / \mathrm{ml}$ ); final methanol concentration in assays of NADH-cytochrome $c$ oxidoreductase and controls was I \% $(\mathrm{v} / \mathrm{v})$. Precautions to ensure that even the most active fractions gave reaction rates proportional to enzyme concentrations and not limited by substrate concentrations have been detailed previously (Poole et al. 1971). The validity of this procedure was confirmed by the satisfactory enzyme recovery figures finally obtained.

Analytical methods. Difference spectra were traced with the Cary spectrophotometer (sometimes fitted with a liquid $\mathrm{N}_{2}$ attachment). Protein was assayed by the method of Lowry, Rosebrough, Farr \& Randall (195I); the standard used was bovine serum albumin (Fraction V, Armour Pharmaceutical Co. Ltd, Eastbourne, Sussex).

Treatment and presentation of results. Enzyme units are expressed as nmol of substrate

* Abbreviations used: IDPase, inosine pyrophosphatase; TPPase, thiamine pyrophosphatase; DNase, deoxyribonuclease; RNase, ribonuclease. 


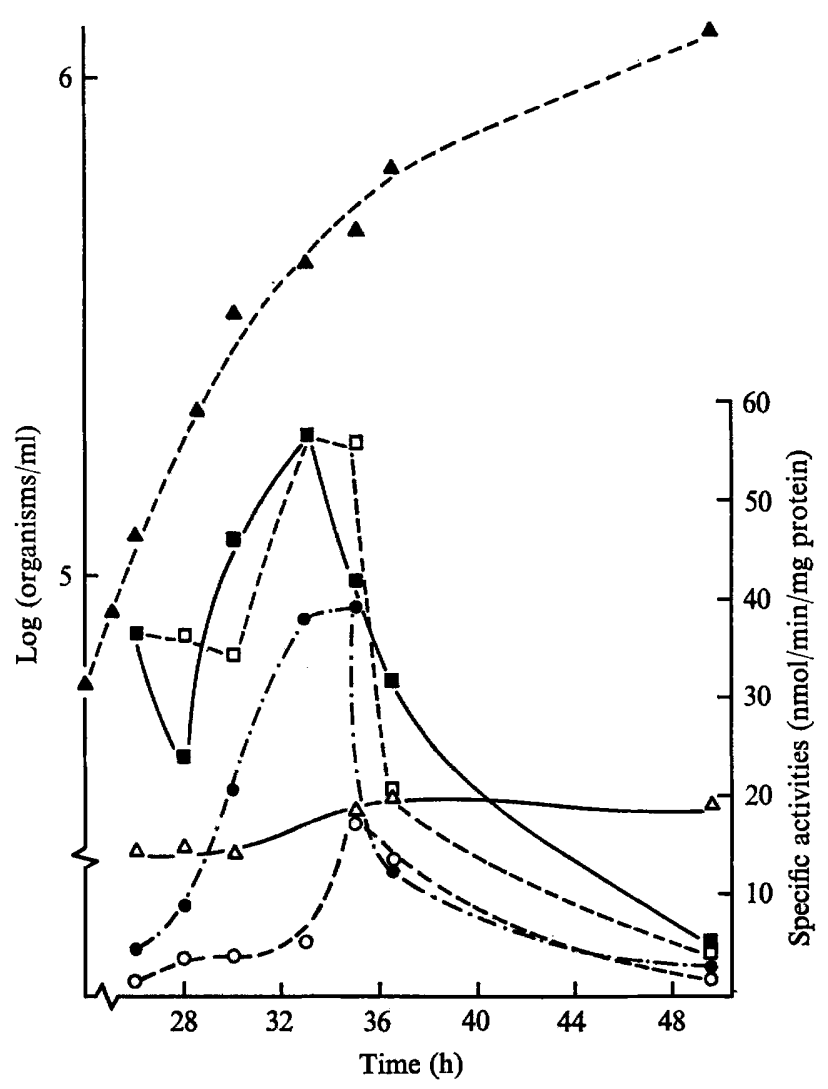

Fig. I. Growth of Polytomella caeca $(\mathbf{\Delta})$, and changes in the specific activities of cytochrome $c$ oxidase ( $\square$ ), succinate cytochrome $c$ oxidoreductase (O), NADH-cytochrome $c$ oxidoreductase $(\square)$, catalase $(\bigcirc)$, and acid $p$-nitrophenyl phosphatase $(\triangle)$.

transformed/min or of measured product formed/min. In the graphical presentations (Fig. 4) vertical lines divide the diagrams at density intervals of $0.05 \mathrm{~g} / \mathrm{ml}$. Percentage sedimentability in high-speed zonal centrifugation experiments is arbitrarily expressed as that proportion of total enzyme units recovered which had sedimented beyond $\mathrm{I} \cdot \mathrm{I} / \mathrm{g} / \mathrm{ml}$ after centrifugation for $6 \times 10^{6} \mathrm{~g}$ min. Values for sedimentation coefficients $\left(s_{20, w}\right)$ were calculated by the method of Halsall \& Schumaker (1969) as detailed by Poole et al. (I97I) except that a computer program devised by Mr M. Statham was employed.

\section{RESULTS}

Changes in specific activities of enzymes during growth. Specific activities of all the enzymes assayed increased during the exponential phase of growth (Fig. $\mathrm{x}$ ) and reached maxima as the growth rate decelerated prior to the stationary phase of growth. Marker enzymes for mitochondria (cytochrome $c$ oxidase) and peroxisomes (catalase) attained their highest specific activities after 33 and $35 \mathrm{~h}$ growth respectively. For all the subcellular fractionations described, organisms were harvested in this late exponential phase of growth.

Fractionation by differential centrifugation. Differential centrifugation yielded a fraction $P_{1}$, containing $31 \%$ of the whole homogenate protein, together with most of the recovered 


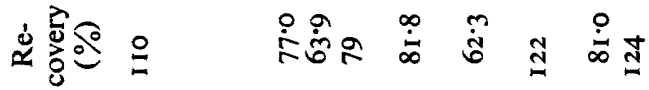

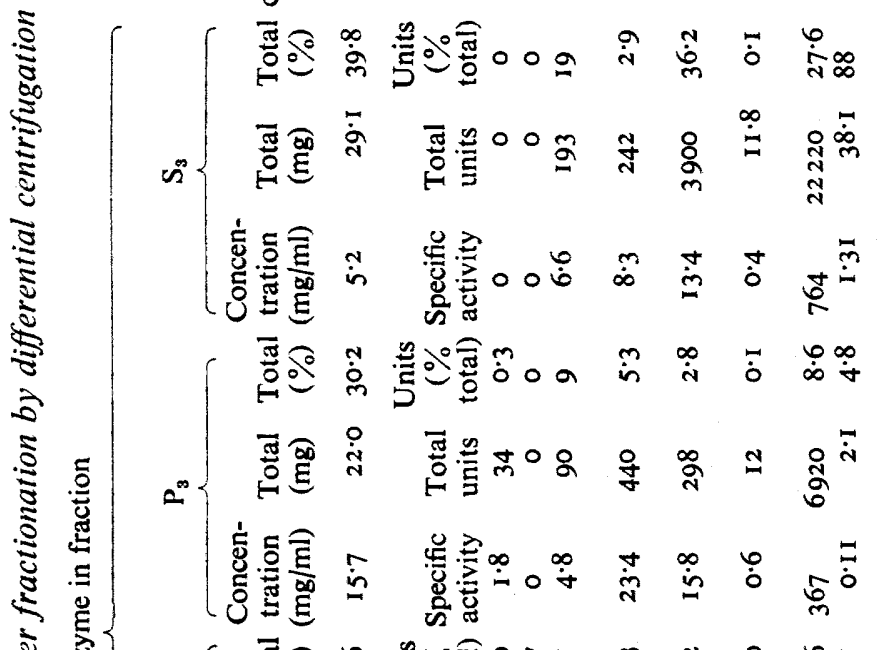

(

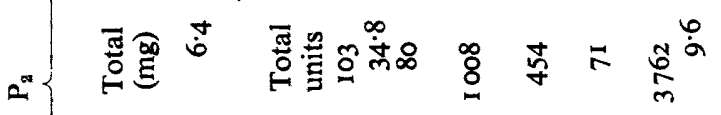

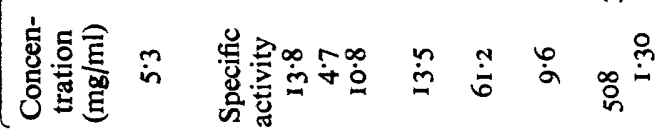

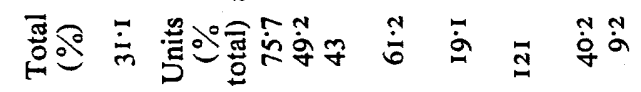

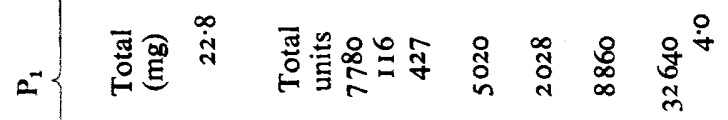

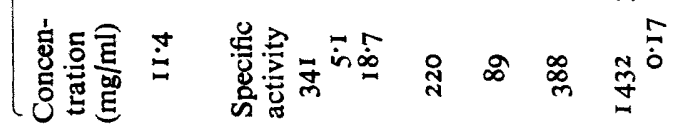

妾

בิ

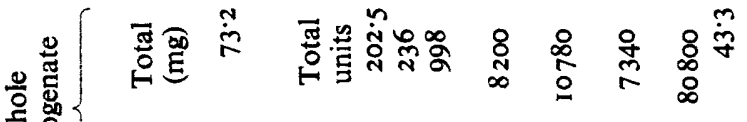

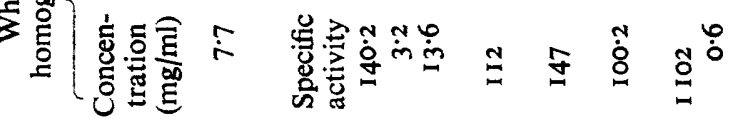

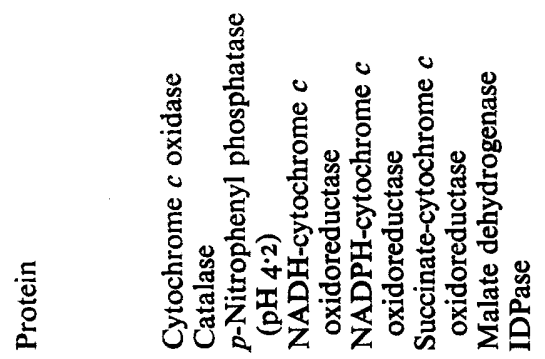




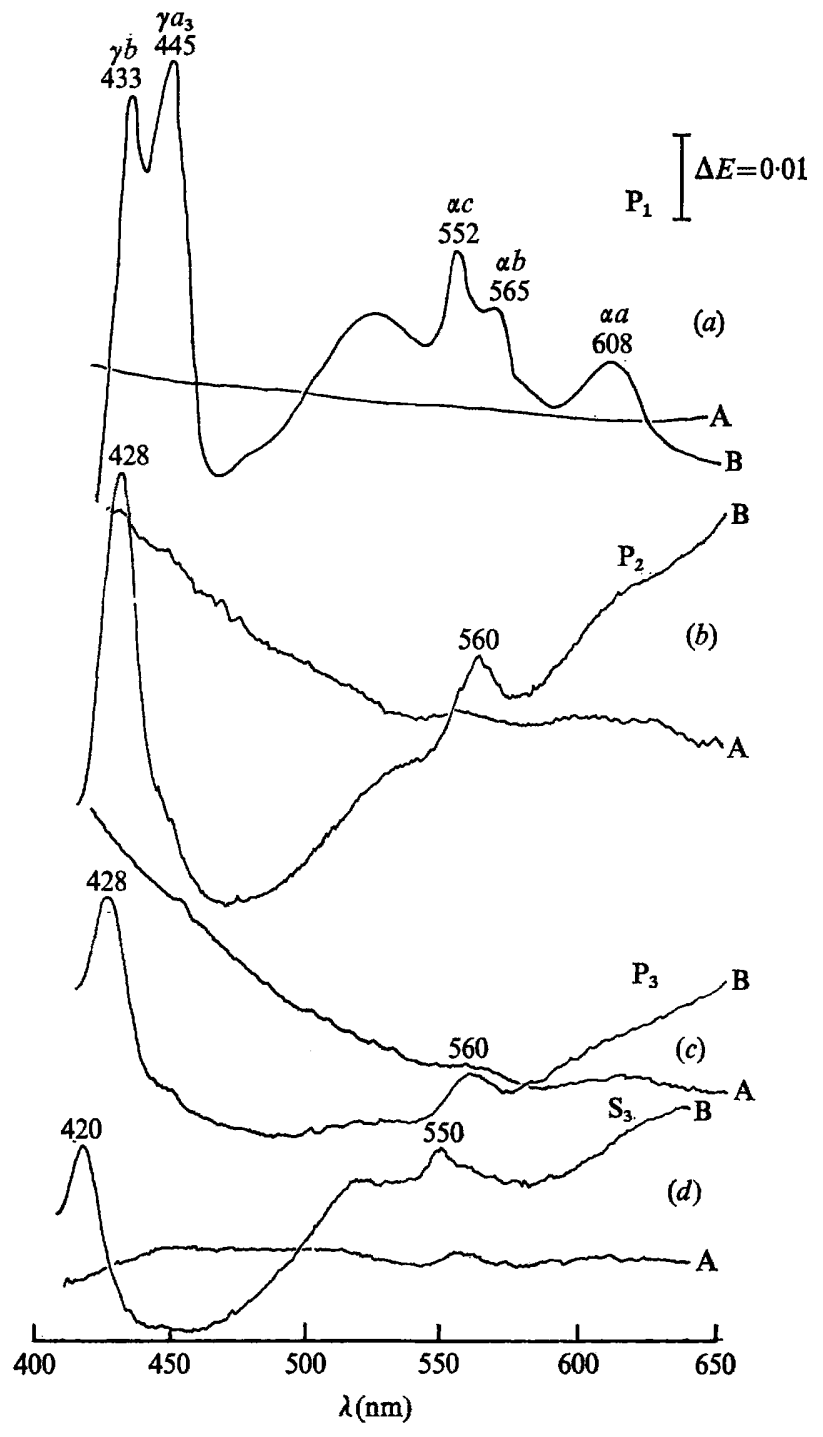

Fig. 2. Difference spectra of fractions obtained from Polytomella caeca by differential centrifugation. Centrifugation procedures detailed in Methods. Baselines were drawn (curves A oxidizedoxidized), and then excess $\mathrm{Na}$-dithionite was added to the sample cuvettes to obtain difference spectra (curves B, dithionite reduced-oxidized). (a) Fraction $P_{1} 6 \mathrm{mg}$ protein $/ \mathrm{ml}$; (b) fraction $P_{2} 4.9 \mathrm{mg}$ protein $/ \mathrm{ml}$; (c) fraction $\mathrm{P}_{3} 4.6 \mathrm{mg}$ protein $/ \mathrm{ml}$ procedure as in $(a)$ except that NADPH (I mg) was' used as reductant in place of dithionite; $(d)$ fraction $S_{3} 9.1 \mathrm{mg}$ protein $/ \mathrm{ml}$.

cytochrome $c$ oxidase and succinate-cytochrome $c$ oxidoreductase, $77 \%$ of the recovered catalase, and approximately $40 \%$ of both the malate dehydrogenase and acid $p$-nitrophenyl phosphatase (Table I). This fraction also contained $6 \mathrm{I} \%$ of the NADH-cytochrome $c$ oxidoreductase, but only $19 \%$ of the NADPH-linked enzyme. Thus, appreciable proportions of both these oxidoreductases and also malate dehydrogenase did not sediment with mitochondria or peroxisomes under these conditions. The 'microsomal' pellets $\mathbf{P}_{\mathbf{2}}$ and $\mathbf{P}_{3}$ contained $27 \%$ of the IDPase, $18 \%$ of the NADH-cytochrome $c$ oxidoreductase and $17 \%$ of the acid $p$-nitrophenyl phosphatase, together with $39 \%$ of the protein. 
(a)

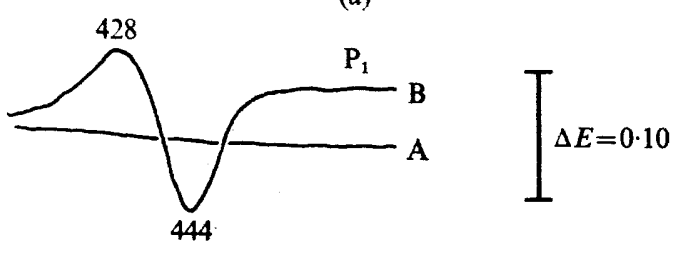

(b)
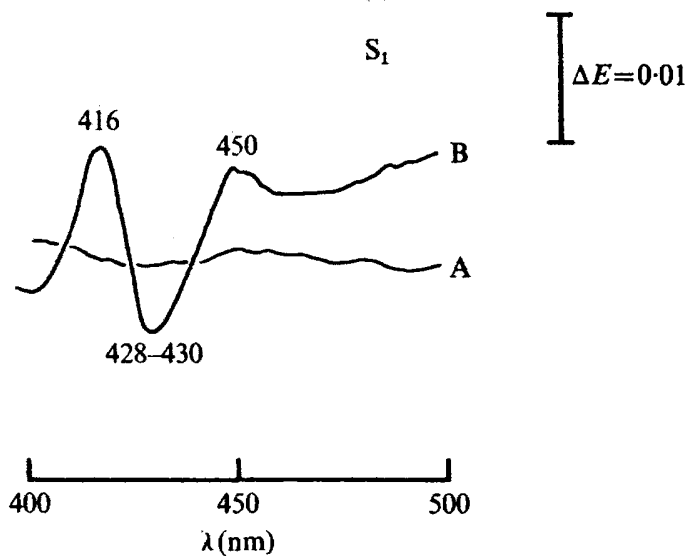

Fig. 3. Carbon monoxide spectra of fractions obtained from Polytomella caeca by differential centrifugation. Centrifugation procedures detailed in Methods. Baselines were drawn (curves A, dithionite reduced-dithionite reduced), the sample cuvette was bubbled with $\mathrm{CO}$, and spectra (curves $\mathrm{B}$ ) drawn. (a) Fraction $P_{1}$ (I I.8 $\mathrm{mg}$ protein $\left./ \mathrm{ml}\right) ;(b)$ fraction $S_{1}(9 \cdot 5 \mathrm{mg}$ protein $/ \mathrm{ml})$.

Difference spectra (at room temperature) of fraction $\mathrm{P}_{1}$ (Fig. $2 a$ ) showed the presence of mitochondrial cytochromes (Lloyd \& Chance, 1968 ); fractions $P_{2}$ and $P_{3}$ both contained a cytochrome $b$ (reducible with NADH, NADPH or dithionite) with absorption maxima at 560 and $428 \mathrm{~nm}$ (Fig. $2 b, c)$. Fraction $\mathrm{S}_{3}$ contained cytochrome $c(550,520,420 \mathrm{~nm}$; Fig. $2 d)$; this may have originated from slightly damaged mitochondria or may reflect a truly cytosolic location. Haemoproteins reacting with carbon monoxide (CO) were found both in the mitochondrial fraction $\left(P_{1}\right)$, and in the postmitochondrial supernatant $\left(S_{1}\right)$ (Fig. 3). The classical cytochrome oxidase spectrum found in fraction $P_{1}$ was different from that of $S_{1}$ which contained cytochrome $P$-4I 6 together with a small amount of cytochrome $P-450$. The trough at 428 to $430 \mathrm{~nm}$ suggested that a $b$-type cytochrome had reacted with $\mathrm{CO}$.

These differential centrifugation results were obtained with a homogenate prepared with Io mM-EDTA in place of $0.5 \mathrm{mM}^{-\mathrm{MgCl}_{2}}$ in the disruption buffer. Essentially similar results for distributions of enzymes or cytochromes were observed when the usual $\mathrm{MgCl}_{2}$-containing disruption buffer was employed.

Fractionation of a whole homogenate by high-speed zonal centrifugation. After centrifugation of a whole homogenate for $165 \mathrm{~min}$ at $35000 \mathrm{rev} . / \mathrm{min}$

$$
\text { ( } \equiv 6 \times 10^{6} \mathrm{~g} \min \text { at the sample zone: } \int_{0}^{t} w^{2} \mathrm{~d} t=\mathrm{I} \cdot 45 \times 10^{11} \mathrm{rad}^{2} \mathrm{~s}^{-1} \text { ) }
$$

the major zone at $\rho=\mathrm{I} \cdot 20$ corresponded to the main zone of sedimentable protein (Fig. $4 a$ ) 


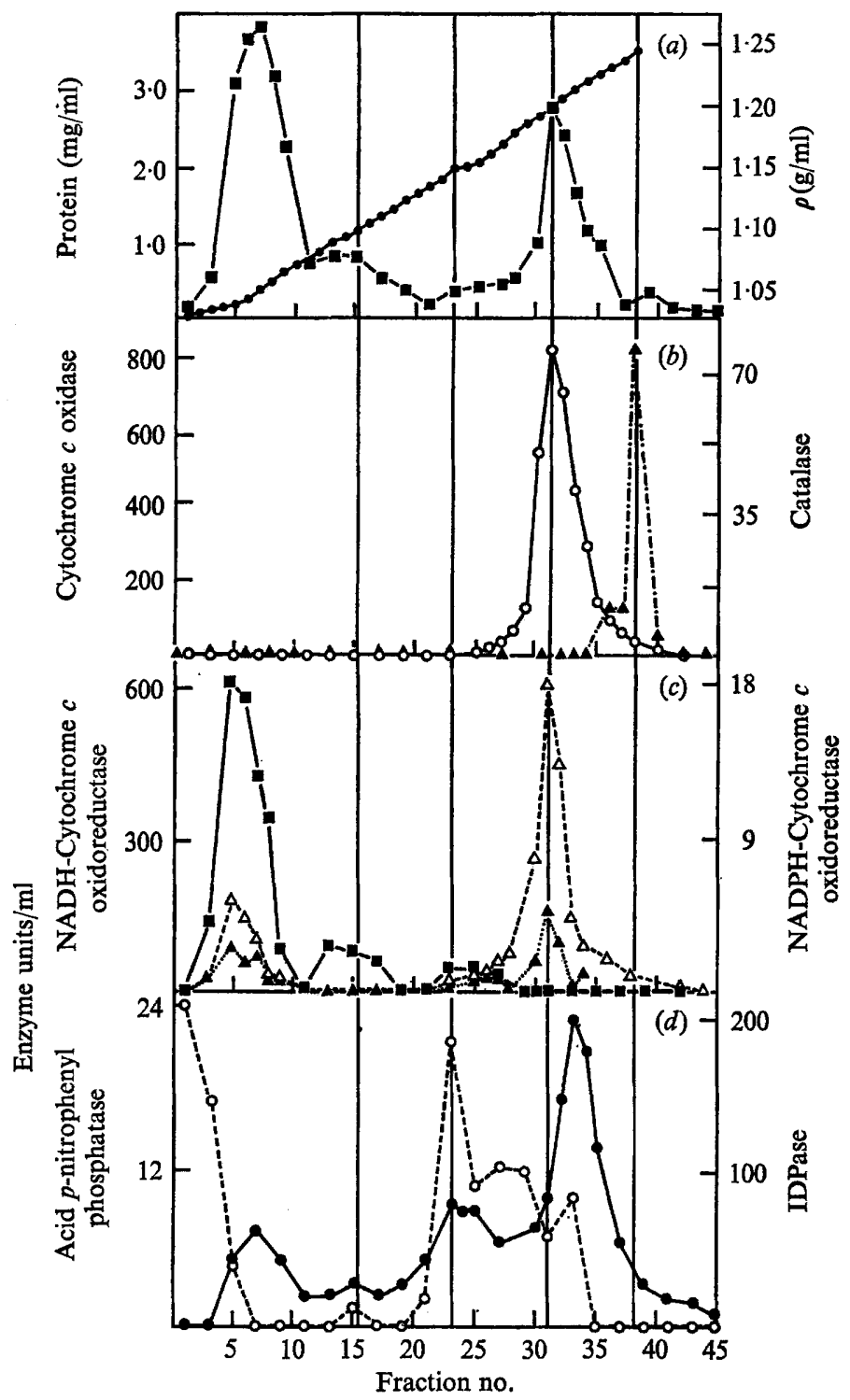

Fig. 4. Fractionation of a whole homogenate of Polytomella caeca. The homogenate $(20 \mathrm{ml})$ contained $544 \mathrm{mg}$ total protein. Whole homogenate was diluted $\mathrm{r}$ in 20 , and volumes of diluted homogenate and of fractions taken for assays were as follows: cytochrome $c$ oxidase, catalase, NADHand NADPH-cytochrome $c$ oxidoreductases, all $0.1 \mathrm{ml}$; protein and acid $p$-nitrophenyl phosphatase, $0.2 \mathrm{ml}$; IDPase $0.5 \mathrm{ml}$. Centrifugation was at $35000 \mathrm{rev} . / \mathrm{min}$ for $165 \mathrm{~min}$

$$
\left(\equiv 6 \times 10^{6} \mathrm{~g} \min \text { at the sample zone: } \int_{0}^{t} w^{2} \mathrm{~d} t=1.45 \times 10^{11} \mathrm{rad}^{2} \mathrm{~s}^{-1}\right) \text {. }
$$

(a) Sucrose density gradient $(\bullet)$ and protein $(\boldsymbol{D})$.

(b) Cytochrome $c$ oxidase $(O)$ and catalase $(\boldsymbol{A})$.

(c) NADH-cytochrome $c$ oxidoreductase in the absence $(\Delta)$ and in the presence $(\Delta)$ of $10 \mu \mathrm{g}$ of antimycin A per $0.1 \mathrm{ml}$ of fraction; NADPH-cytochrome $c$ oxidoreductase ( $\square$ ).

$(d)$ Acid $p$-nitrophenyl phosphatase (O) and IDPase (O). Specific activities of enzymes in the whole homogenate and recoveries (in parentheses) were as follows: cytochrome $c$ oxidase $5.6(60 \%)$, catalase $14.7(25 \%)$, NADH-cytochrome $c$ oxidoreductase $87.4(66 \%)$, NADPH-cytochrome $c$ oxidoreductase $2 \cdot 1(88 \%)$, acid p-nitrophenyl phosphatase $7 \cdot 7(51 \%)$ and IDPase 14.7 . Recovery of IDPase was very low due to the presence of a phosphate-utilizing system in the whole homogenate. 


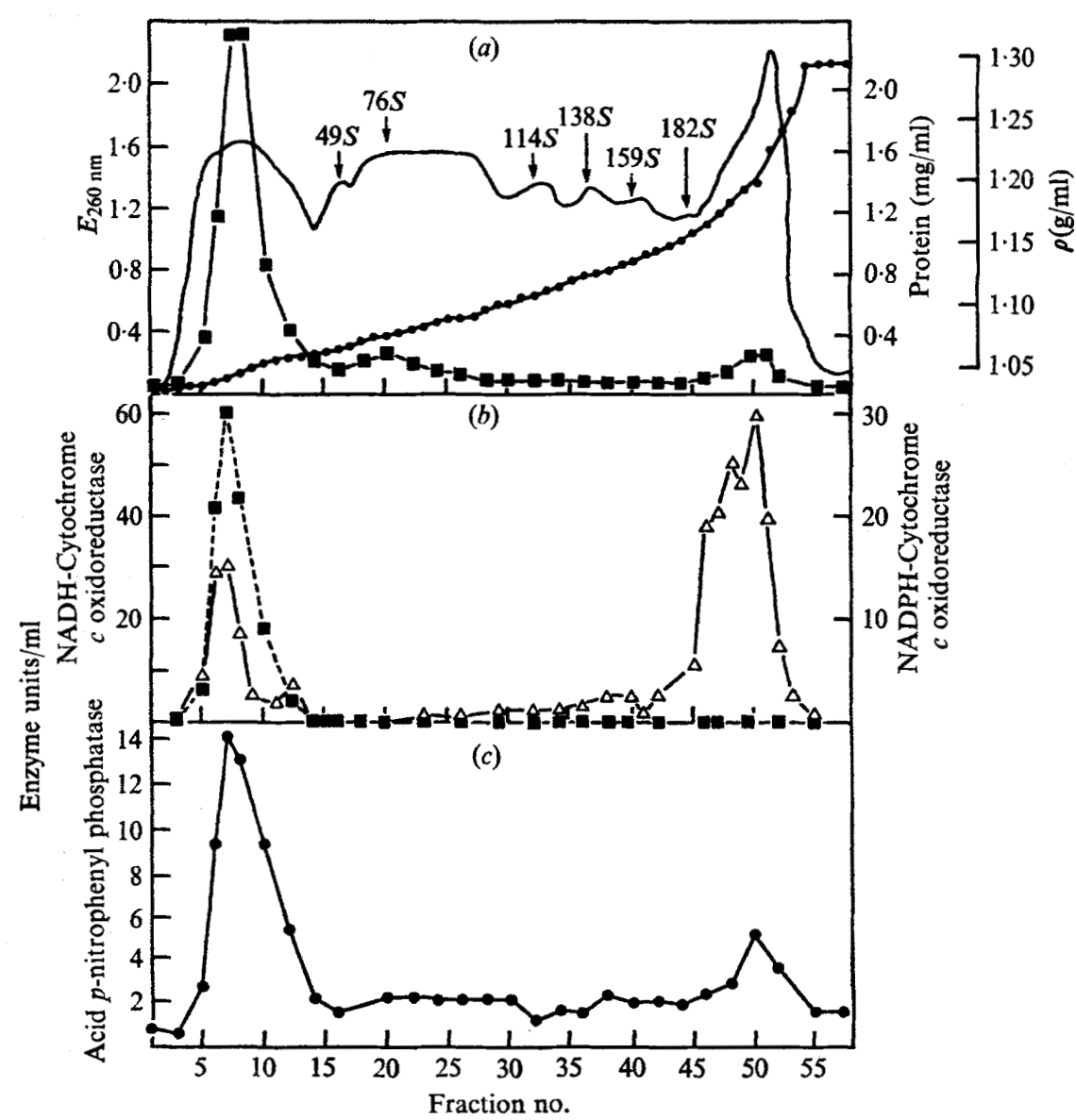

Fig. 5. Subfractionation of post mitochondrial supernatant $\left(\mathrm{S}_{1}\right)$ of Polytomella caeca. The fraction $\left(S_{1}\right)(14.5 \mathrm{ml})$ contained $136.7 \mathrm{mg}$ total protein, it was diluted $\mathrm{I}$ in 20 , and volumes of diluted homogenate and of fractions then taken for assays were as follows: NADH- and NADPH-cytochrome $c$ oxidoreductases, both $0.1 \mathrm{ml}$; protein and acid $p$-nitrophenyl phosphatase, $0.2 \mathrm{ml}$. Centrifugation was at $35000 \mathrm{rev} . / \mathrm{min}$ for $165 \mathrm{~min}$

$$
\left(\equiv 6 \times 10^{6} \mathrm{~g} \text { min at the sample zone: } \int_{0}^{t} w^{2} \mathrm{~d} t=1 \cdot 45 \times 10^{11} \mathrm{rad}^{2} \mathrm{~s}^{-1}\right) .
$$

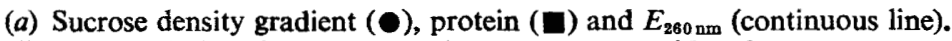

(b) NADH- $(\triangle)$ and NADPH- ( $\boldsymbol{\omega})$ cytochrome $c$ oxidoreductases.

(c) Acid $p$-nitrophenyl phosphatase (๑).

and the single symmetrical peak of cytochrome oxidase (Fig. $4 b$ ). The position of this mitochondrial population also coincided with that of the sedimentable portion of NADHcytochrome $c$ oxidoreductase (Fig. $4 c$ ) which was more than $80 \%$ inhibited by antimycin A. This zone contained no detectable NADPH-cytochrome $c$ oxidoreductase (Fig. $4 c$ ). The recovered catalase was entirely sedimentable (Fig. $4 b$ ), and its profile indicates that the peroxisomes, having attained their equilibrium density, $(\rho=\mathrm{I} \cdot 25)$ were well separated from mitochondria. The catalase activity was low in Polytomella extracts, and this accounts for the low recoveries obtained. However, the separation of peroxisomes by this one-step method resulted in a $20-$ fold purification of catalase over the original whole homogenate and resulted 


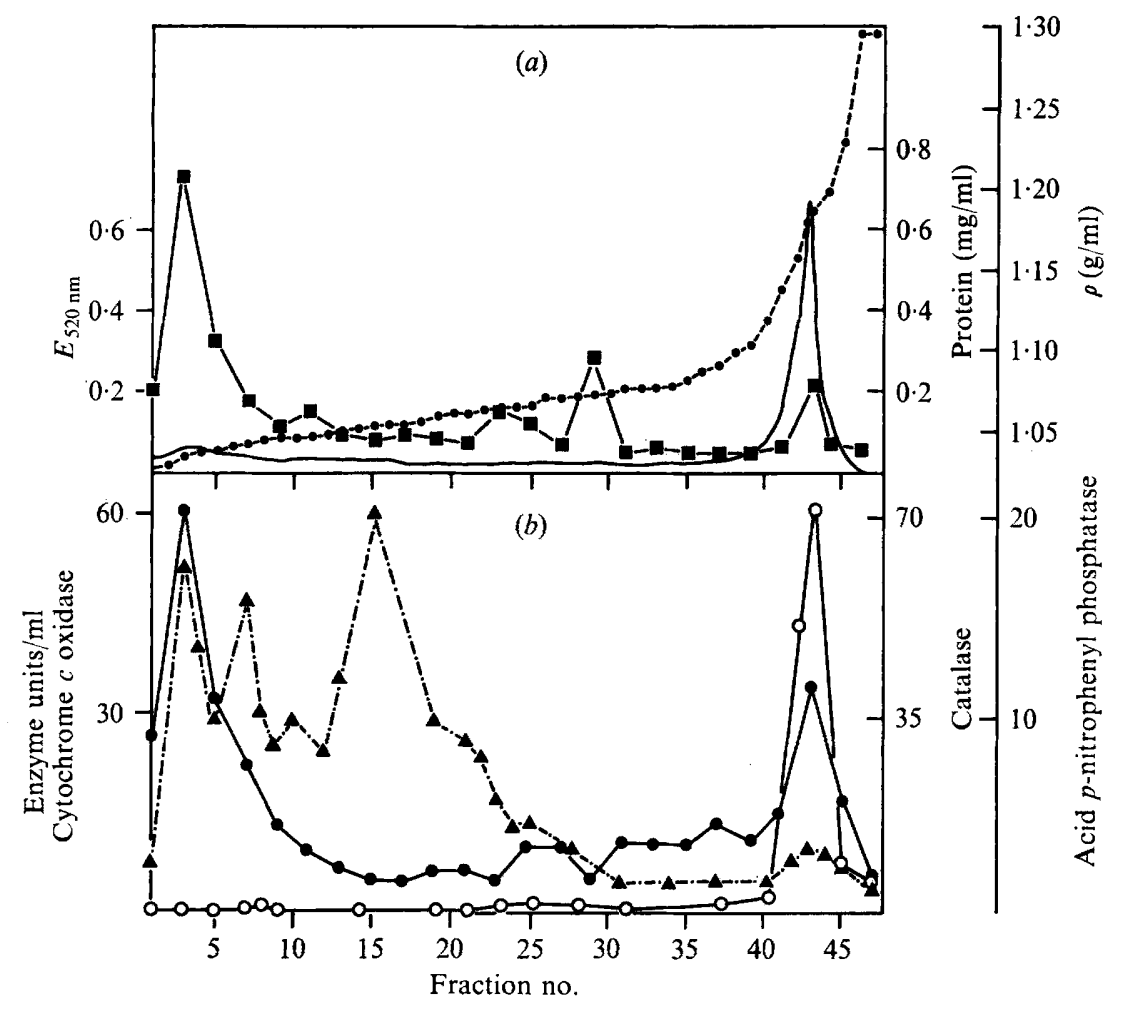

Fig. 6. Rate-zonal separation of peroxisomes and mitochondria from a whole homogenate of Polytomella caeca. The homogenate $(\mathrm{I} 6 \mathrm{ml})$ contained $96 \mathrm{mg}$ total protein. Whole homogenate was diluted $I$ in 20 , and volumes of diluted homogenate and of fractions then taken for assays were as follows: cytochrome $c$ oxidase and catalase $0.1 \mathrm{ml}$; protein and acid $p$-nitrophenyl phosphatase $0.2 \mathrm{ml}$. Centrifugation was at $18500 \mathrm{rev} . / \mathrm{min}$ for $2 \mathrm{~min}$

$$
\text { ( } \equiv 6.28 \times 10^{4} g \mathrm{~min} \text { at the sample zone: } \int_{0}^{t} w^{2} \mathrm{~d} t=\mathrm{I} \cdot 42 \times 10^{9} \mathrm{rad}^{2} \mathrm{~s}^{-1} \text { ). }
$$

(a) Sucrose density gradient ( $\bullet$ ), protein ( $\boldsymbol{(})$ and $E_{520 \mathrm{~nm}}$ (continuous line).

(b) Cytochrome $c$ oxidase $(O)$, catalase $(\boldsymbol{\Lambda})$ and acid $p$-nitrophenyl phosphatase $(\boldsymbol{O})$.

Table 2. Specific activities of enzymes and their recoveries in whole homogenate and postmitochondrial supernatant $\left(S_{1}\right)$

\begin{tabular}{|c|c|c|c|c|c|c|}
\hline & & & \multicolumn{4}{|c|}{ Enzyme units } \\
\hline & \multicolumn{2}{|c|}{$\begin{array}{l}\text { Specific } \\
\text { activities of } \\
\text { enzymes in }\end{array}$} & \multirow{2}{*}{$\begin{array}{l}\text { Recovery } \\
\frac{\left(\mathbf{P}_{\mathbf{1}}+\mathbf{S}_{1}\right)}{\mathrm{WH}} \%\end{array}$} & \multirow{2}{*}{$\begin{array}{c}\text { Recovered } \\
\text { in } \\
\text { fractions } \\
\text { from } \\
\mathbf{S}_{1}(\%)\end{array}$} & \multirow{2}{*}{$\begin{array}{l}\text { Total } \\
\text { units of } \\
\text { WH in } \\
S_{1}(\%)\end{array}$} & \multirow{2}{*}{$\begin{array}{l}\text { Sedimen- } \\
\text { tibility } \\
\text { in } S_{1}(\%)\end{array}$} \\
\hline & WH & $S_{1}$ & & & & \\
\hline Protein & - & - & IOI & II 6 & 75.5 & $22 \cdot 8$ \\
\hline NADH-cytochrome $c$ oxidoreducta & $94 \cdot 8$ & $46 \cdot 0$ & 76 & 84 & $36 \cdot 4$ & 74 \\
\hline NADPH-cytochrome $c$ oxidoreductase & $92 \cdot 4$ & $86 \cdot 0$ & $7 \mathrm{I}$ & 109 & $69 \cdot 4$ & $3 \cdot 0$ \\
\hline Acid $p$-nitrophenyl phosphatase & 14.9 & $14 \cdot 0$ & 112 & 88 & $82 \cdot 5$ & $33 \cdot 8$ \\
\hline
\end{tabular}


in fractions with negligible contamination by mitochondria. Acid p-nitrophenyl phosphatase distribution (Fig. $4 d$ ) was very heterogeneous but showed two distinct sedimentable zones; the major one was at $\rho=\mathrm{r} \cdot 2 \mathrm{I}$ and was not well separated from the mitochondrial zone. The second zone of this acid hydrolase was located at around $\rho=\mathrm{I} \cdot \mathrm{I} 5$; this region of the gradient also contained a zone of NADPH-cytochrome $c$ oxidoreductase, a small proportion of the total of the NADH-linked enzyme, and IDPase (Fig. $4 d$ ). NADPH-cytochrome $c$ oxidoreductase was $75 \%$ non-sedimentable, although a broad zone of particles containing this enzyme had moved from the starting zone (Fig. $4 \mathrm{c}$ ).

Low-temperature spectra indicated that fraction 32 contained the full complement of mitochondrial cytochromes as previously described by Lloyd \& Chance (1968). Fraction 6 contained a $c$-type cytochrome ( $\alpha$-band at $549 \mathrm{~nm}$ ); fraction 25 showed the presence of a cytochrome $b$ (Soret band at $428 \mathrm{~nm}$ ); fraction 38 showed absorption maxima at 590,554 and $426 \mathrm{~nm}$.

Subfractionation of postmitochondrial supernatant $\left(S_{1}\right)$ by high-speed zonal centrifugation. After subjecting $S_{1}$ to conditions of zonal centrifugation similar to those employed for whole homogenates, the profile of absorbancy at $260 \mathrm{~nm}$ indicated the presence of several zones of sedimenting material (Fig. $5 a$ ). Values of $s_{20 \text {, w }}$ were computed, and indicated that the broad zone of ribosome monomers had a median sedimentation coefficient of $76 \mathrm{~S}$. Positions and sedimentation coefficients of ribosome dimers, trimers and tetramers were as shown in Fig. $5 a$, the identities of these were confirmed by electron microscopy. A major zone of $260 \mathrm{~nm}$ absorbing material was heterogeneously distributed through the steep region of the gradient; this coincided with a major portion of the sedimentable NADH-cytochrome $c$ oxidoreductase which was completely antimycin A-insensitive (Fig. $5 b$ ). In other experiments the distribution of particles containing this latter enzyme was further resolved into three populations $(\rho=\mathrm{I} \cdot \mathrm{I} 5, \mathrm{I} \cdot \mathrm{I} 8$ and $\mathrm{I} \cdot 2 \mathrm{I})$. NADPH-cytochrome $c$ oxidoreductase (Fig. $5 b)$ was almost entirely non-sedimentable. Acid $p$-nitrophenyl phosphatase (Fig. $5 c$ ) was again very heterogeneous. A summary of specific activities, recoveries and sedimentabilities of protein and enzymes in whole homogenate and in fractions $P_{1}$ and $S_{1}$ are shown in Table 2.

Low-speed zonal centrifugation of whole homogenates. Fig. 6 shows a rate-separation of mitochondria from peroxisomes. Thus after centrifugation for $2 \mathrm{~min}$ at $18500 \mathrm{rev}$./min

$$
\left(=6.28 \times 10^{4} \mathrm{~g} \text { min at the sample zone: } \int_{0}^{t} w^{2} \mathrm{~d} t=\mathrm{I} \cdot 42 \times 10^{9} \mathrm{rad}^{2} \mathrm{~s}^{-1}\right)
$$

mitochondria had sedimented to fraction 43 (median $s_{20, \mathrm{w}}=24.4 \times 10^{3} \mathrm{~S}$ ) whereas the catalase-containing organelles showed a broad size distribution [median $s_{20, \mathrm{w}}$ (calculated for fraction 15$)=4.4 \times 10^{3} \mathrm{~S}$ ]. Acid $p$-nitrophenyl phosphatase-containing organelles were also heterogeneous with respect to size. Values for the mean radii of mitochondria and peroxisomes calculated from the sedimentation data were 0.70 and $0.28 \mu \mathrm{m}$ respectively; it is evident from the distributions that the peroxisomes were of a broad size range.

Assays for other possible marker enzymes. The following enzymes, which have been shown to be present in peroxisomes of other micro-organisms (de Duve, I969; Müller, I969; Hughes, Lloyd \& Brightwell, 1970), were not present at detectable levels of activity in whole homogenates of Polytomella caeca (limit of sensitivity of assays in $\mathrm{nmol} / \mathrm{min} / \mathrm{mg}$ of protein are given in parentheses): urate oxidase $(<0.082)$, D- or L-amino acid oxidases $(0.03), \mathrm{L}-\alpha-$ hydroxy acid oxidase $(<0.03)$, glyoxylate reductase $(<0.28)$, glycollate oxidase $(<0.15)$. Isocitrate lyase was present, but was nearly all ( $>95 \%$ ) non-sedimentable. Acid hydrolases which where not detectable in whole homogenates included: sodium $\beta$-glycerophosphatase $(<5 \cdot 2), \alpha$ - and $\beta$-galactosidases, $\alpha$ - and $\beta$-glucosidases and $N$-acetyl glucosaminidase (all 
$<0.03), \beta$-glucuronidase $(<0.05)$, aryl sulphatase $(<0.13)$, DNase and RNase $(<0.02)$ and acid protease ( $<0 . \mathrm{I} \mu \mathrm{g}$ protein hydrolysed $/ \mathrm{min} / \mathrm{mg}$ extract protein).

Possible 'microsomal' marker enzymes assayed but not detected included alkaline phosphatase $(<0.5)$, TPPase $(<3 \cdot 0)$ and glucose-6-phosphatase $(<5 \cdot 2)$.

\section{DISCUSSION}

The conditions employed in these experiments give good preservation of several of the membrane structures seen in Polytomella caeca, Lloyd et al. (I970). It is possible to sediment mitochondria entirely and to obtain a postmitochondrial supernatant containing little cytochrome oxidase, antimycin A-sensitive NADH-cytochrome $c$ oxidoreductase or spectrally detectable mitochondrial cytochromes $a, a_{3}$ or $b$. Thus the portion of the NADHcytochrome $c$ oxidoreductase which is antimycin A-insensitive but which sediments from whole homogenate to about the same density as mitochondria is probably non-mitochondrial, although we cannot exclude the possibility that it might have originated from outer mitochondrial membrane. There is no detectable mitochondrial NADPH-cytochrome $c$ oxidoreductase, making Polytomella caeca unusual in this respect (see Lloyd et al. 197I; Cartledge \& Lloyd, 1972).

Analysis of the postmitochondrial supernatant indicates that the isolation procedures are suitable for separations of polysomes. The highly developed Golgi apparatus seen in sections of the organism (Lloyd, et al. 1970) is probably not released intact, and has not been identified in electron micrographs of isolated fractions. Possibly acid $p$-nitrophenyl phosphatase, nicotinamide nucleotide-linked cytochrome $c$ oxidoreductases and IDPase (enzymes often associated with Golgi membranes of mammalian origin; Morré et al. 1970) found in fractions $\mathrm{P}_{2}, \mathrm{P}_{3}$ and in sucrose density gradients between $\rho=\mathrm{I} \cdot \mathrm{IO}$ and $\mathrm{I} \cdot \mathrm{I} 8$ may be associated with 'microsomal' vesicles. Cytochrome $b$ detected at $\rho=\mathrm{I} \cdot 15$ (and in fraction $\mathrm{P}_{2}$ and $\mathrm{P}_{3}$ ) is likely to be involved in the microsomal electron-transport chain. Failure to detect acid hydrolases other than acid p-nitrophenyl phosphatase poses the question of the existence of lysosomes in this organism, as true lysosomes would contain a whole range of latent acid hydrolases (de Duve \& Wattiaux, 1966). A functional role for the peroxisome also awaits elucidation, as many of the enzymes often located in this organelle in other organisms could not be found in Polytomella. Low temperature spectra indicated the presence of a dithionitereducible haemoprotein with a distinctive absorption spectrum in fractions rich in peroxisomes; this observation warrants further investigation. We have also been unable to confirm the report of Haigh \& Beevers (I964) that the glyoxylate cycle enzymes of Polytomella are particulate. An independent report of the isolation of peroxisomes from Polytomella has appeared while this work was in progress (Gerhardt \& Berger, 197I): the only enzyme assayed by these workers was catalase.

We acknowledge the continued interest of Professor D. E. Hughes and assistance with electron-microscopy techniques by Miss S. Davies. R. A. C. was the holder of an M.R.C. Studentship. 


\section{REFERENCES}

Anderson, N. G., Waters, D. A., Fisher, W. D., Cline, G. B., Nunley, C. E., Elrod, L. H. \& Rankin, C. T. (1967). Analytical techniques for cell fractions. V. Characteristics of the BXIV and BXV zonal centrifuge rotors. Analytical Biochemistry 2r, 235-252.

Cartledge, T. G., CoOper, R. A. \& Lloyd, D. (1971). Subcellular fractionation of eukaryotic microorganisms. In Separations with Zonal Rotors, pp. v-4.I-v-4.16. Edited by E. Reid. Guildford: University of Surrey Press.

CARTLEDGE, T. G. \& LlOYD, D. (1972). Subcellular fractionation by differential and zonal centrifugation of aerobically-grown, glucose derepressed Saccharomyces carlsbergensis. Biochemical Journal 126, 381-393.

Cooper, R. A., Jones, M. G., Venables, S. E. \& Lloyd, D. (1969). Subcellular fractionation of Polytomella caeca by zonal centrifugation. Biochemical Journal 114, $65 \mathrm{P}$.

DE Duve, C. (1969). Evolution of the peroxisome. Annals of New York Academy of Sciences 168, 369-381.

De Duve, C., Berthet, J. \& Beaufay, H. (1959). Gradient centrifugation of cell particles. Theory and applications. Progress in Biophysics and Biophysical Chemistry 9, 326-369.

DE Duve, C. \& Wattiaux, R. (1966). Functions of lysosomes. Annual Review of Physiology 28, 435-492.

GerhardT, B. \& Berger, C. (197I). Microbodies und Diaminobenzidin-Reaktion in den Acetat-Flagellaten Polytomella caeca und Chlorogonium elongatum. Planta 100, 155-166.

Haigh, W. G. \& Beevers, H. (1964). The glyoxylate cycle in Polytomella caeca. Archives of Biochemistry and Biophysics 107, 152-157.

Halsall, H. B. \& Schumaker, V. N. (1969). Sedimentation coefficients in the zonal centrifuge. Analytical Biochemistry 30, 368-376.

Hughes, D. E., Lloyd, D. \& BRightwell, R. (1970). Structure, function and distribution of organelles in prokaryotic and eukaryotic microbes. Symposium of the Society for General Microbiology 20, $295-322$.

Lloyd, D., Brightwell, R., Venables, S. E., ROACH, G. I. \& TURNer, G. (197I). Subcellular fractionation of Tetrahymena pyriformis by zonal centrifugation: changes in activities and distribution of enzymes during the growth cycle and on starvation. Journal of General Microbiology 65, 209-223.

Lloyd, D. \& ChANCE, B. (1968). Electron transport in mitochondria isolated from the flagellate Polytomella caeca. Biochemical Journal ro7, 829-837.

Lloyd, D., Evans, D. A. \& Venables, S. E. (1968). Propionate assimilation in the flagellate Polytomella caeca. An inducible mitochondrial enzyme system. Biochemical Journal 109, 897-907.

Lloyd, D., Evans, D. A. \& Venables, S. E. (1970). The effects of chloramphenicol on growth and mitochondrial function of the flagellate Polytomella caeca. Journal of General Microbiology 6r, 33-4I.

Lowry, O. H., Rosebrough, N. J., Farr, A. L. \& Randall, R. J. (195I). Protein measurement with the Folin phenol reagent. Journal of Biological Chemistry 93, 265-275.

MAHLER, H. R. (1955). DPNH cytochrome reductase (animal). Methods in Enzymology 2, 688-693.

Morré, D. J., Hamilton, R. H., Mollenhauer, H. H., Mahley, R. W., Cunningham, W. P., Cheetham, R. D. \& LEQUIRE, V. S. (1970). Isolation of a Golgi apparatus-rich fraction from rat liver. I. Method and morphology. Journal of Cell Biology 44, 484-491.

Müller, M. (1969). Peroxisomes of Protozoa. Annals of New York Academy of Sciences 168, $292-301$.

Novikoff, A. B. \& Heus, M. (1963). A microsomal nucleoside diphosphatase. Journal of Biological Chemistry 238, $710-716$.

OCHOA, S. (1955). Malic dehydrogenase from pig heart. Methods in Enzymology r, 735-739.

Poole, R. K., Nicholl, W. G., TuRner, G., ROACH, G. I. \& Lloyd, D. (1971). Sedimentation characteristics of mitochondria, peroxisomes and lysosomes from the ciliate protozoon Tetrahymena pyriformis strain ST after chloramphenicol inhibited growth. Journal of General Microbiology 67, 16I-173.

Pringsheim, E. G. (1955). The genus Polytomella. Journal of Protozoology 2, 137-I45.

SMITH, L. (1955). Cytochromes $a, a_{1}, a_{2}$, and $a_{3}$. Methods in Enzymology 2, 732-740. 